\title{
CheV1 Plays an Important Role in Chemotaxis of Vibrio Cholerae
}

\author{
Geetha Hiremath, So-Ichiro Nishiyama, and Ikuro Kawagishi
}

\begin{abstract}
The complete genome sequence of $V$. cholerae has revealed the presence of four CheV's, namely putative $\mathrm{CheV}$, CheV1, CheV2 and CheV3, along with the three chemotaxis-related signaling systems designated as System I, II and III. To determine the roles of the $\mathrm{CheV}$ proteins, whose genes are located outside of the che gene clusters, we examined their cellular localization and then their roles in chemotaxis. Among the four CheV's, CheV1 plays a major role in chemotaxis as observed with swarm assay and fluorescence microscopy, suggesting its involvement in System II.
\end{abstract}

Index Terms-Chemotaxis, fluorescence microscopy, fusion proteins, localization, signal transduction, swarm assay.

\section{INTRODUCTION}

Vibrio cholerae, the etiological agent of cholera disease, is a highly motile bacterium possessing three sets of proteins with similarity to conventional chemotaxis-signaling proteins (Che proteins) and a single polar flagellum. Central to the chemotactic signal transduction, best studied in E. coli [1]- [5], is a two-component regulatory system where phosphate is relayed from histidine kinase CheA to the response regulator CheY with the help of other Che proteins, resulting in motor switch from counterclockwise to clockwise direction and hence reorientation of the cell. The receptors, which are homodimeric transmembrane proteins, localize at a cell pole and form a huge hexagonal array with a trimer of dimmers as building unit. CheW and CheA, as well as other Che proteins, target to the receptor cluster [6], [7] to form an exquisite signaling supramolecular complex or signallosome. Receptor clustering is critical for signal amplification and adaptation. The complete genome sequence of $V$. cholerae revealed the presence of several chemotaxis-related gene homologs [8]. Most of the ORFs encoding the different Che homologs are clustered in three different regions distributed on both chromosomes (Fig. 1). Similarly, several other organisms, including $M$. Xanthus [9], P. aerugionosa [10], $R$. sphaeroides [11] and others have been reported to contain multiple chemotaxis operons. Among the three Che Systems

Manuscript received November 14, 2012; revised January 26, 2013. This work was partially supported by a Grant-in-Aid for Scientific Research from the Japan Society for Promotion of Science and the MEXT-supported Program for the Strategic Research Foundation at Private Universities, 2008-2012.

Geetha Hiremath is with the Research center for Micro-Nano technology, Hosei university, Japan (email: geetha.2225@gmail.com).

So-Ichiro Nishiyama is with Dept. of Frontier Bioscience, Faculty of Bioscience and Applied Chemistry, Hosei University, Japan.

Ikuro Kawagishi is with Dept. of Frontier Bioscience, Graduate School of Engineering, Hosei University. of $V$. cholerae, System II alone directly mediates chemotaxis as deletion of CheA2 and also CheY3 of System II impaired chemotaxis [12], [13].

The genome sequence also showed a similar set of proteins other than the core signal transduction proteins, namely $\mathrm{CheV}$ proteins, which are not present in $E$. coli but are reported in $B$. subtilis [14], [15], H. pylori [16], [17], S. enterica [18]. These $\mathrm{CheV}$ proteins are the fusion proteins consisting of a N-terminal CheW-like (adaptor-like) and a C-terminal CheY-like (response regulator-like) domains. In $V$. cholerae, there are four $\mathrm{CheV}$ proteins namely, putative $\mathrm{CheV}$, CheV1, CheV2 and CheV3, the genes of which are not in any of the three che gene clusters but are scattered over the genome. The che $V$ genes of $H$. pylori differentially affect motility [19] and cheV gene in $B$. subtilis is necessary for full chemoreceptor-CheA coupling and also for adaptation. The role of these cheV genes is not known in $V$. cholerae as none of them is located in any of the che clusters nor there is any data to show their involvement in chemotaxis. The aim of this study is to identify the roles of these CheV's, for which we first tried to characterize and group them into different Che Systems.

\section{EXPERIMENTAL PROCEDURES}

\section{A. Bacterial Strains}

The $V$. cholerae O395N1, a classical strain $(\Delta c t x A)$ [20] wild-type for chemotaxis, was used for all experiments. The $E$. coli strain DH5 $\alpha$ was used for cloning.

\section{B. Construction of Plasmids}

The target genes were cloned as in-frame fusions to the green fluorescent protein (GFP) gene by using pTrc-HisB-based plasmids, pTrc-HisB-GFP (for N-terminal fusion) and pDS1050 (for C-terminal fusion) vectors. The PCR amplified products were digested with restriction enzymes BsrGI-XbaI and NheI-XhoI, the resulting fragments were cloned between their respective restriction sites of pTrc-His-B and pDS1050 vectors. Expression of the fusion proteins were verified by immunoblot using anti-GFP antibodies. All insertions were verified by restriction analysis and sequencing.

\section{Swarm Assay for Chemotaxis}

Swarm assays were performed with tryptone semisolid agar (1\% Bacto-Tryptone [BD], 0.5\% NaCl, 0.3\% Bactoagar [BD]) supplemented with $50 \mu \mathrm{g} / \mathrm{ml}$ ampicillin and $100 \mu \mathrm{M}$ IPTG. A single colony or $2 \mu \mathrm{l}$ of overnight cultures were spotted onto the agar plate and incubated at $30^{\circ} \mathrm{C}$ for appropriate time. 
Chromosome I (2.9 Mb)

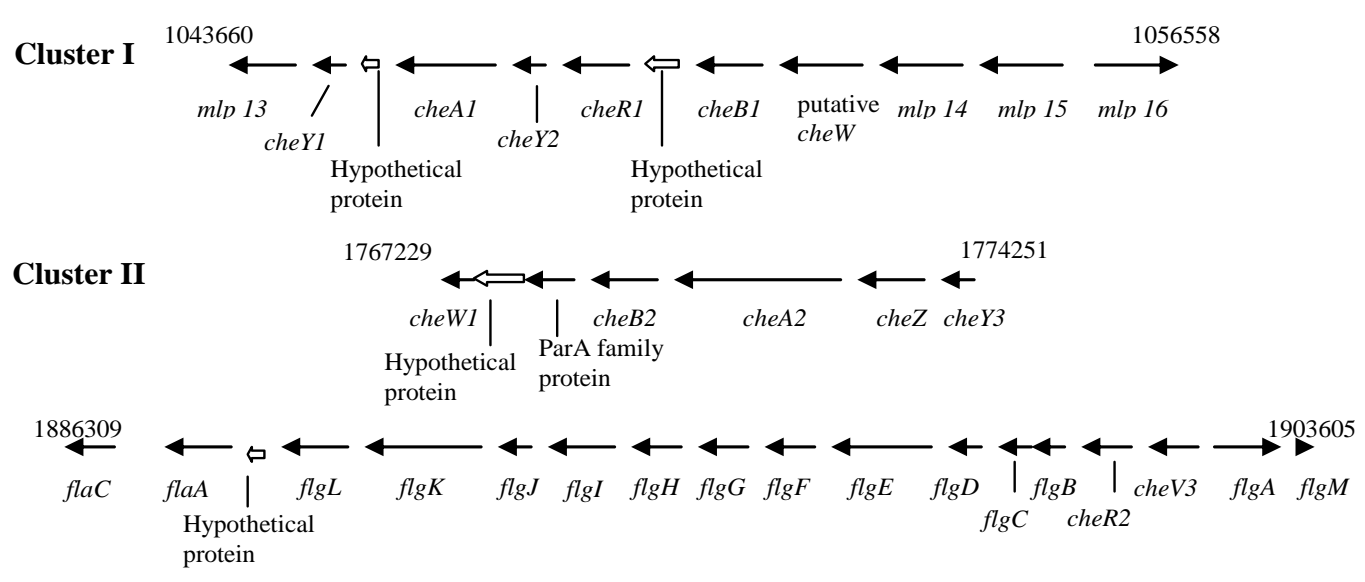

Chromosome II (1.07 Mb)

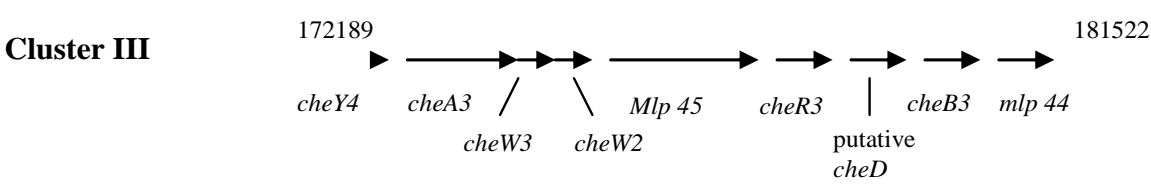

Fig. 1. A schematic diagram of the three che and fla gene clusters located on the two chromosomes in V. cholerae (classical biotype). Adapted from Gosink $e t$ al., 2002

\section{Growth Conditions and Fluorescence Microscopy}

Cells were grown at $30^{\circ} \mathrm{C}$ in tryptone broth $(1 \%$ Bacto Tryptone [BD], $0.5 \% \quad \mathrm{NaCl}, \quad 0.5 \% \quad[\mathrm{w} / \mathrm{v}]$ glycerol) supplemented with $50 \mu \mathrm{g} / \mathrm{ml}$ ampicillin. To express the proteins, overnight cultures were diluted 1:50 in TG medium with or without IPTG and were shaken for 4 hours. A cell suspension was applied to a coverslip and observed under a microscope (Olympus 1X71). The images were recorded and processed by using a cooled charge-coupled-device camera (Hamamatsu C10600) and the software Meta Morph version 7.6 .

\section{E. Immunoblotting}

The samples were aliquoted from the fluorescence microscopy samples and checked for the protein expression. Proteins were denatured on SDS-PAGE and transferred onto PVDF membranes using semi-dry western blot transfer and detected using anti-GFP antibodies (Cell signaling).

\section{RESULTS}

\section{A. Localization of System II and CheV Proteins}

The Initial analysis of the $\mathrm{CheV}$ proteins among the other bacterial species gave an idea about their involvement in chemotaxis. To understand their role in $V$. cholerae, GFP fusions to all the four $\mathrm{CheV}$ proteins were constructed and their subcellular localization was compared with the GFP fusions of Che components of Systems I, II and III using fluorescence microscopy. The fluorescence images showed that all the four $\mathrm{CheV}$ proteins localized to the pole, in a way similar to that of CheW1 of System II (Fig. 2A). All the proteins were expressed and detected by immunoblotting using anti-GFP antibodies (Fig. 2B). The CheW1 and other
System II components that are involved in chemotaxis constitutively localized to the pole, whereas the components of System I and III did not localize and were scattered throughout the cell (data not shown). These results suggest that $\mathrm{CheV}$ proteins might be involved in chemotaxis along with System II components.

A

System II

CheW1-GFP
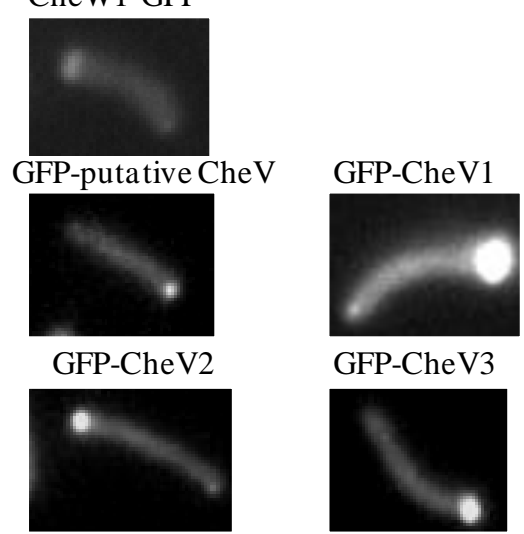

B

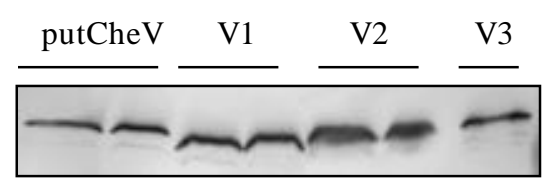

Fig. 2. Fluorescence images of CheVs and CheW1 fused to GFP in $V$. cholerae. Wild type (O395N1) cells expressing GFP-putative CheV (GFP-putCheV), GFP-CheV1, GFP-CheV2 andGFP-CheV3 were grown to late logarithmic phase and observed under microscopy (A). Immunoblotting of GFP fused $\mathrm{CheV}$ proteins. The constructed plasmids were introduced into wildtype(O395N1) strain. Lysates of cells were subjected to SDS-PAGE (15\%) followed by immunoblotting with anti-GFPantibody (B).

\section{B. Swarm Assay}

To elucidate the roles of the four $\mathrm{CheV}$ homologs in $V$. 
cholerae is difficult as none of their genes are located in any che cluster. Hence, we first tried to classify them into three different Che systems by checking the effects of their overexpression on swarming ability in a semisolid agar plate. The overproduction of System II components affects the chemotaxis of $V$. cholerae due to the jamming of the signaling system. To observe if CheV's behaved similarly, all the four cheV genes and the cheWl gene cloned downstream of the trc promoter were electroporated into the $\mathrm{Che}^{+}(\mathrm{O} 395 \mathrm{~N} 1)$ strain. A single colony from each transformant was stabbed into a $0.3 \%$ tryptone agar plate and observed for swarming. Whereas overproduction of $\mathrm{CheV} 1$ and $\mathrm{CheV} 2$ interfered with chemotaxis, putative $\mathrm{CheV}$ had a slight effect, and CheV3, which is located near the flagellar cluster, did not have any significant effect Fig.3. B1. Growth rates of cells overproducing each $\mathrm{CheV}$ homolog were similar to that of wild-type cells (data not shown). The average diameters of the swarm rings from three different experiments are plotted as shown in Fig. 3. B2 and are in the following order: pTrc $>/=$
GFP-CheV3> GFP-putative CheV> GFP-CheV2> GFP-CheV1. CheV2 and CheV1 both interfered with swarming ability, where CheV1showed a higher rate of interference indicating its role in chemotaxis.

\section{CONCLUSIONS}

The complete genome sequence of $V$. cholerae showed the presence of a unique set of modular proteins other than the core signal transduction proteins, namely $\mathrm{CheV}$ proteins, which are not present in $E$. coli, but are present in other bacteria such as B. subtilis, $H$. pylori and $S$. typhimurium. The presence of four $\mathrm{CheV}$ proteins along with the three Che systems indicates the presence of a complex signal transduction pathway in $V$. cholerae. In this study, we have focused on distinguishing CheV's into different systems and also to identify their role in chemotaxis. The presence of $\mathrm{N}$-terminal CheW suggests its role in early stages of signal

A1 $+0.1 \mathrm{mM}$ IPTG

B1
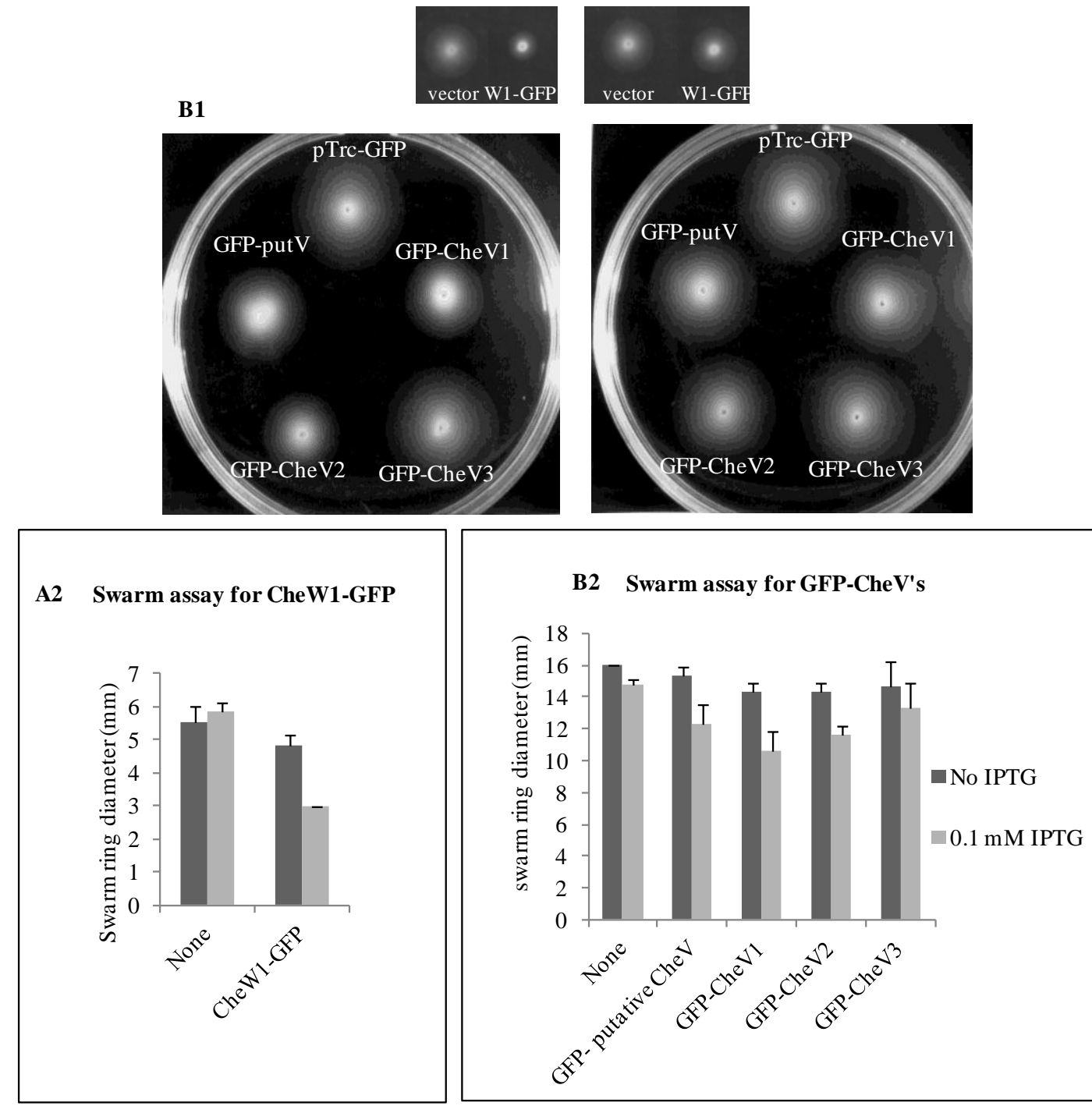

Fig. 3. Swarm assay. Swarming ability of overexpressed CheW and CheV fused to GFP proteins and the vector in wild type cells in the presence or absence of IPTG. A single colony from the transformants were stabbed onto ampicillin-supplemented $0.3 \%$ tryptone agar plates (intriplicates) without or with IPTG and incubated at $30^{\circ} \mathrm{C}(\mathrm{A} 1$ and $\mathrm{B} 1)$. The average diameter of the swarm rings from the three different experiments are plotted in the above graph with the error bars (A2 and B2). 
Transduction. V. cholerae has four $\mathrm{CheW}$ proteins that are clustered into three different Systems, among which CheW1 of System II is involved in chemotaxis. In our study, we showed that CheV1 is an essential chemotaxis protein. Overexpression of CheV1 protein inhibited swarming ability of wild-type $0395 \mathrm{~N} 1$ cells as seen with the CheW1 protein. This is the same effect seen upon overexpression of the homologous E. coli CheW [21] where it has been clearly shown that overexpression of the protein is equivalent to its absence in swarming assay. The sequence alignment of the CheW-like domains of all the $V$. cholerae CheV's with the $V$. cholerae and E. coli $\mathrm{CheW}$ proteins showed that these domains have the conserved arginine residue known to modulate CheA kinase activity. There is also significant charge and residue conservation within $\mathrm{CheW}$ regions responsible for chemoreceptor binding. These findings thus suggest that the $V$. cholerae CheV's likely retain CheW-like ability to interact with both chemoreceptors and CheA. Our results showing the polar localization of these $\mathrm{CheV}$ proteins similar to that of System II Che proteins and also the effect of CheV1 on swarming ability argue that CheV1 may be involved in the formation and/or regulation of the receptor-kinase complex.

\section{FUTURE PERSPECTIVES}

To further validate that among the four CheV's, CheV1 is involved in chemotaxis, mutant strains carrying a deletion in each of the cheV genes need to be constructed. A more detailed study of the each CheW-like and CheY-like domain is required to explain the precise role and mechanism of the individual $\mathrm{CheV}$ proteins and to further our understanding in the chemotaxis of $V$. cholerae.

\section{REFERENCES}

[1] J. P., "Armitage, bacterial tactic responses," Adv Microb Physiol vol. 41, pp. 229-289, 1999.

[2] J. J. Falke, R. B. Bass, S. L. Butler, S. A. Chervitz, and M. A. Danielson, "The two-component signaling pathway of bacterial chemotaxis: a molecular view of signal transduction by receptors, kinases, and adaptation enzymes," Annu Rev Cell Dev Biol, vol. 13, pp 457-512, 1997.

[3] M. D. Manson, "Bacterial motility and chemotaxis," Adv Microb Physiol, vol. 33, pp. 277-346, 1992.

[4] V. Sourjik and H. C. Berg, "Localization of components of the chemotaxis machinery of Escherichia coli using fluorescent protein fusions," Mol. Microbiol, vol. 37, pp. 740-751, 2000.

[5] J. B. Stock and M. G. Surette, "Chemotaxis. In Escherichia coli and Salmonella typhimurium: Cellular and Molecular Biology," 2nd edn. F. C. Neidhardt, R. Curtiss III, J. J. Ingram, E. C. C. Lin, K. B. Low, B. Magasanik, et al. (eds). Washington, DC: American Society for Microbiology Press, vol. 1, pp. 1103-1129, 1996.

[6] J. R. Maddock and L. Shapiro, "Polar location of the chemoreceptor complex in the Escherichia coli cell," Science, vol. 259, pp. 1717-1723, 1993.

[7] M. M. L. Rosario, K. L. Frederick, G. W. Ordal, and J. D. Helmann, "Chemotaxis in Bacillus subtilis requires either of two functionally redundant CheW homologues," J. Bacteriol, vol. 176, pp. 2736-2739, 1994.

[8] J. F. Heidelberg, J. A. Eisen, W. C. Nelson, R. A. Clayton, M. L. Gwinn, R. J. Dodson, D. H. Haft, E. K. Hickey, J. D. Peterson, L. Umayam, et al, Nature, vol. 406, pp. 477-483, 2000.

[9] Z. Yang, Y. Geng, D. Xu, H. B. Kaplan, and W. Shi, "A new set of chemotaxis homologues is essential for Myxococcus xanthus social motility," Mol. Microbiol, vol. 30, pp. 1123-1130, 1998.

[10] C. K. Stover, X. Q. Pham, A. L. Erwin, S. D. Mizoguchi, P. Warrener, M. J. Hickey, F. S. Brinkman, W. O. Hufnagle, D. J. Kowalik, M. Lagrou, R. L. Garber, L. Goltry, E. Tolentino, S. Westbrock-Wadman,
Y. Yuan, L. L. Brody, S. N. Coulter, K. R. Folger, A. Kas, K. Larbig, R. Lim, K. Smith, D. Spencer, G. K. Wong, Z. Wu, and I. T. Paulse, "Complete genome sequence of Pseudomonas aeruginosa PA01, an opportunistic pathogen," Nature, vol. 406, pp. 947-948, 2000.

[11] A. C. Martin, G. H. Wadhams, and J. P. Armitage, "The roles of the multiple CheW and CheA homologues in chemotaxis and in chemoreceptor localization in Rhodobacter sphaeroides," Mol. Microbiol, vol. 40, pp. 1261-1272, 2001.

[12] K. K. Gosink, R. Kobayashi, I. Kawagishi, and C. C. Hase, J. Bacteriol, vol. 184, pp. 1767-1771, 2002.

[13] A. Hyakutake, M. Homma, M. J. Austin, M. A. Boin, C. C. Hase, and I. Kawagishi, "Only one of the five CheY homologs in Vibrio cholerae directly switches flagellar rotation," J. Bacteriol, vol. 187, pp. 8403-10, 2005.

[14] K. L. Fredrick and J. D. Helmann, "Dual chemotaxis signaling pathways in Bacillus subtilis: a UD-dependent gene encodes a novel protein with both CheW and CheY homologous domains," J. Bacteriol, vol. 176, pp. 2727-2735, 1994

[15] M. S. Pittman, M. Goodwin, and D. J. Kelly, "Chemotaxis in the human gastric pathogen Helicobacter pylori: different roles for $\mathrm{CheW}$ and the three $\mathrm{CheV}$ paralogues, and evidence for CheV2 phosphorylation," Microbiology, vol. 147, pp. 2493-2504, 2001.

[16] R. A. Alm, L. S. L. Ling, D. T. Moir, and 20 other authors, "Genomic sequencing comparison of two unrelated isolates of the human gastric pathogen Helicobacter pylori," Nature, vol. 397, pp. 176- 180, 1999.

[17] J. F. Tomb, O. White, A. R. Kerlavage, and 39 other authors, "The complete genome sequence of the gastric pathogen Helicobacter pylori," Nature, vol. 388, pp. 539-547, 1997.

[18] J. Frye, J. E. Karlinsey, H. Felise, B. Marzolf, N. Dowidar, M. McClelland, and K. T. Hughes, J. Bacteriol, vol. 188, pp. 2233-2243, 2006.

[19] A. C. Lowenthal, C. Simon, A. S. Fair, K. Mehmood, K. Terry, S. Anastasia, and K. M. Ottemann, "A fixed-time diffusion analysis method determines that the three cheV genes of Helicobacter pylori differentially affect motility," Microbiology, vol. 155, pp. 1181-1191, 2009.

[20] J. J. Mekalanos, D. J. Swartz, G. D. Pearson, N. Harfort, F. Groyne, and M. De Wilde, "Cholera toxin genes: nucleotide sequence, deletion analysis and vaccine development," Nature, vol. 306, no. 5943, pp. 551-7, 1983

[21] D. A. Sanders, B. Mendez, D. E. Koshland, "Role of the CheW protein in bacterial chemotaxis: overexpression is equivalent to absence," $J$. Bacteriol, vol. 171, pp. 6271-6278, 1989.

Geetha Hiremath obtained her B.Sc. degree in Microbiology in 2001 and M.Sc. degree in Biotechnology in 2003 from Bangalore University. She was awarded with MEXT (Monbukagakusho) scholarship to complete her Ph.D. in Japan. She completed her Ph.D. in 2010 from Graduate Scool of Engineering, Hosei University, Japan for her studies on "Subcellular localization of chemotaxis-related signaling proteins in Vibrio cholerae". Since 2010, she has been working as a postdoctoral fellow at Research Center for Micro-Nano Technology, Hosei University, Japan where she analyses different chemotaxis-related signaling components of $V$ cholerae.

So-Ichiro Nishiyama obtained his B.Sc. degree in 1992 and M.Sc. degree in 1994 from Nagoya University. He completed his Ph.D. at Division of Biological Science, Graduate School of Science, Nagoya University in 1998. Later he joined as a postdoctoral fellow at Department of Biology, University of Utah (1998-2001). After his return to Japan, he worked as an assistant professor and lecturer at Department of Microbiology, School of Dentistry, Aichi-Gakuin University (2001-2007). Since 2007, he has been working as postdoctoral fellow and a part-time lecturer at Department of Frontier Bioscience, Hosei University. His major field of research field is molecular biology and bacteriology.

Ikuro Kawagishi obtained his B.Sc. degree (1983) and M.Sc. degree (1985) from University of Tokyo. He completed his Ph.D. at Department of Botany, Graduate School of Science, University of Tokyo in 1990. He worked as a postgraduate fellow (1988-1990) and a postdoctoral associate (1990-1991) at Department of Molecular Biophysics and Biochemistry, Yale University. After his return to Japan, he worked as an assistant professor at Department of Molecular Biology (reorganized into Division of Biological Science, Graduate School), Nagoya University (1991-1997). In 1997, he was promoted to be an associate professor at Division of Biological Science, Graduate School, Nagoya University. Since 2007, he has been working as a Professor at Department of Frontier Bioscience, Faculty of Engineering (reorganized into Faculty of Bioscience and Applied Chemistry), Hosei University. His major field of study is molecular biology, biophysics and bacteriology. 